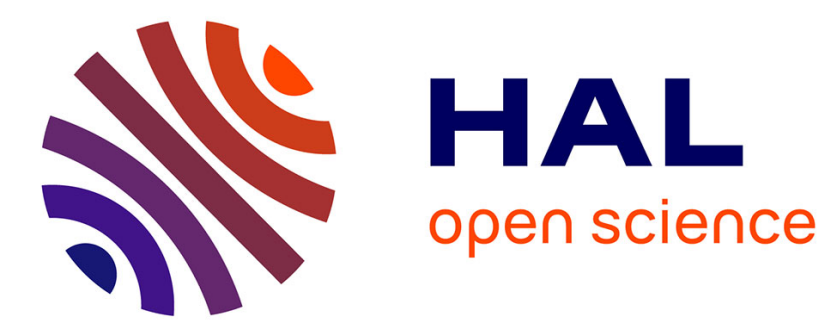

\title{
Conflicts of Interest, Information Quality and Management Decision
}

\author{
Saeed Askary, Shekar S. Shetty
}

\section{To cite this version:}

Saeed Askary, Shekar S. Shetty. Conflicts of Interest, Information Quality and Management Decision. 17th Conference on e-Business, e-Services and e-Society (I3E), Oct 2018, Kuwait City, Kuwait. pp.305314, 10.1007/978-3-030-02131-3_27 . hal-02274146

\section{HAL Id: hal-02274146 \\ https://hal.inria.fr/hal-02274146}

Submitted on 29 Aug 2019

HAL is a multi-disciplinary open access archive for the deposit and dissemination of scientific research documents, whether they are published or not. The documents may come from teaching and research institutions in France or abroad, or from public or private research centers.
L'archive ouverte pluridisciplinaire HAL, est destinée au dépôt et à la diffusion de documents scientifiques de niveau recherche, publiés ou non, émanant des établissements d'enseignement et de recherche français ou étrangers, des laboratoires publics ou privés. 


\title{
Conflicts of Interest, Information Quality and Management Decision
}

\author{
Saeed Askary and Shekar S. Shetty \\ Gulf University for Science and Technology (GUST), Hawally, Kuwait \\ askary.s@gust.edu.kw ; shetty.s@gust.edu.kw
}

\begin{abstract}
The existence of conflict of interests (COI) within different firms' level of management is often cited as the reason for the relationship for low information quality and ineffective decision making. We reveal how COI affects negatively decision making through low information quality longer time to produce information quality, shrinking optimal information quantity, and increasing in the information cost. Although, COI has been studied extensively by different organizational studies, there is no research showing how to measure the effect of COI on information quality from mathematical modeling perspective. Since effective and efficient management decisions closely depend on information quality, this paper provides the solutions to this problem.
\end{abstract}

Keywords: Conflict of Interest, Cost, Information Quality, Management Decision, Timeliness.

\section{Introduction}

Conflict of interests (COI) is one of the complicated organizational dilemma in current organizational enviornment in which analyzing, investigating, and yet suggesting an all-inclusive solution is demanding [4],[7],[9]. This paper shows that COI could affect adversely the quality, quantity and cost of good information. Managers, at different organizational level and to make critical decisions, need to access quality of information at a reasonable cost on-time. To show how COI affects the information quality and the negatively impact on business sustainability thorough increasing different business risks, this paper measure the COI damages and provides solutions to decrease or mitigate the effects.

Information and assets are two main resources almost all enterprises requiring to protect them are part of management responsibilities through designing and implementing an effective internal control system. By considering that information is an integral part of decision making process, the question that how COI can affect negatively on this process would be a significant research question. COI is one of multifaceted ethical problems within organization and measuring how and in what extent COI can affect management decision making gives a tool for manager to handle the problem. The purpose of this study is to measure what aspects of the information are more affected by COI and how the cost and time to produce the reliable information would be increased [14].

One argument in corporate governance is the impact of COI on ownership structure [3]. The importance of corporate governance practices to reduce the COI between managers and shareholders is to reduce earning management techniques. Regardless of considering frauds or illicit acts, earnings management would negatively affect the usefulness of annual reports presented by management to users, which later users apply the information as reliable way for the user decision-making process. Net income is one of the users' sensitive information lead to make judgments about managers in which can be manipulated through earning management techniques because of COI.

The issue of COI is not neglected by the US legislations. The Sarbanes-Oxley Act (SOX) of 2002 approached to the subject of COI in four sections: Section 206 (audit independence), Section 402 (financial disclosures), Section 406 (code of ethics for senior financial officers), and Section 501 (securities analysis). Section 206, 402, and 501 of the Act amended to Section 10A, 13, and 15C of the 
Securities Exchange Act of 1934. SOX (2002) highlighted the importance of COI in corporate governance, audit independence, financial disclosure, ethics and professional conducts in these sections. However, section 404 of the Act clearly says that management is responsible to design, implement, and maintained an effective and sound internal control system. The main purpose of the system is to protect assets and producing reliable and quality information. The cost of internal control system assumes to lower the cost of producing quality information. However, to produce more reliable and relevant information, firms pay for assurance services (e.g. audit of financial statements, review, etc.) and nonassurance services (e.g. consultancy, tax, etc.).

The rest of this paper organized as follow. First, this study reviews current literature about the effects of COI on information quality. From section two to five, our emphasis will be given to those COI aspects that affect greatly on enhancing information quality by looking at reducing information cost, cutting delay in delivering of the information (timeliness), and optimal quantity of the relevant and reliable information. Also the link between COI and corporate governance theories would be shown by analysis of some relevant cases and provide solutions to remove or mitigating the effect of COI on corporate governance mechanism. Discussion part will be presented at section seven and conclusion in the last section.

\section{Information quality}

Management decisions, to have effective and efficient corporate results, vastly depend on information quality. Information quality should have those characteristics that is free from material misstatements, errors, frauds, but are also timely, complete, reliable, and relevance. Eventually, eliminating COI will cause manager to make great decision to bring valuable corporate results for the organizations. When information quality is integrated with professional management skills, then immense benefits should be normally great success the organizational goals. Information quality depend heavily on data quality. To be relevant and reliable information, the amount of information, timeliness and cost of the information supposed to be at the optimal points. That is, information quantity would be at the optimal points, producing the information cost is less than information benefits and the time of information availability to the decision makers is at the right time of management request.

Nelson detailed the different losses of COI within every organization. The following table shows three categories and effects of the losses: operation, legal and the public relations through direct, indirect and long-term effects [11].

Table 1: Organizational losses of COI

\begin{tabular}{|l|l|l|l|}
\hline \multirow{4}{*}{ Loss Categories } & Direct & Indirect & Long-term \\
\hline \multirow{4}{*}{ Operation } & Staff time & Staff time & Staff burnout \\
\cline { 2 - 4 } & Ethic consultants time & $\begin{array}{l}\text { Staff \& consultants } \\
\text { stress }\end{array}$ & Staff turnover \\
\cline { 2 - 5 } & & Staff consultants & Additional staff needed \\
\cline { 2 - 5 } & & Decreased staff moral & \\
\hline \multirow{4}{*}{ Legal } & Legal consultants & Staff time & Additional staff needed \\
\cline { 2 - 5 } & Legal fees & Staff stress & Budget adjustment \\
\cline { 2 - 5 } & Settlement fees & Reputation risk & Higher malpractice costs \\
\cline { 2 - 4 } & Court charges & & \\
\hline
\end{tabular}




\begin{tabular}{|l|l|l|l|}
\hline \multirow{4}{*}{ Public Relation } & Public relationship time & Rebuilt public image & Negative public image \\
\cline { 2 - 4 } & Consultant time & Staff work diverted & Loss of market share \\
\cline { 2 - 4 } & Advertising costs & Staff morale and stress & $\begin{array}{l}\text { Decreased philanthropic } \\
\text { support }\end{array}$ \\
\hline
\end{tabular}

As the table implies, the COI deteriorates the information quality due to secrecy. The COI push the information producers have preference not to show all sufficient, relevance and reliable information as revealing the information will act against their benefits. Thus, hiding of that quality information protect their benefits and damage other interested group in the organization. One of theories in information quality emphasizing on COI and degree of information quality is the information asymmetric theory.

\subsection{Theory of Information Asymmetry}

Information asymmetry theory is based on the study of Akerlof (1970) in which the behavior of buyers and sellers of used goods is analyzed by abandoning the hypothesis of perfect information on the market and assuming the contrary, the uncertainty of regarding the quality of products purchased [1]. The arguments of Akerlof result by analyzing the market place of some product where the seller has more information about the quality of products than the buyer. Akerlof concluded that hypothetical information difficulties can lead either to the collapse of the entire market, or to its transformation by adverse selection, being chosen the poor quality products instead of the higher quality ones. Initially, the theory of asymmetry information marked the first research in the field of buyer behavior but then rapidly expanded in financial theory and considerably affected the classical theories of the firm [2].

The hypothesis concerning the informational asymmetry is closely related to the agency theory and to the existence of agency relationships. Dividend and other financing policies adopted by directors would create different interests between the directors and shareholders. In this context, the rational for dividends paid to shareholders is provided, although it is known that they will pay an additional tax for this additional income. An answer in the "signaling" theory area is that dividends can be a good sign for future investments, the investor pay more for a share because, on the market, a big level of dividend is interpreted as a good sign which will mean a higher price of the shares. Likewise, "signals" of a strong company can be emitted through debt policy because it is considered that a strong company is one which can afford a high rate of indebtedness in order to finance ambitious investment projects. In conclusion, effective corporate governance will determine the reduction of informational asymmetry effect and prevent the manifestation of unfair actions of the managers to gain prestige and reputation but affecting the company's growth.

\subsection{Agency Theory}

One of central corporate governance theories is agency theory, known as principal-agent problem. The fundamental theories related to agency theory that can be closely associated with corporate governance are steward theory, hazard theory, stakeholder theory, resource dependence theory, transaction cost theory, political theory, and ethical theories. Agency theory describes relationship between the owners of a company and its managers, the agent based on a contract which the first part (the principal) engages with the second part (the agent) to perform stewardship service on behalf of the principals [8].

Alleging the interests of managers and shareholders should be through corresponding interests of managers in their decision-making circumstances with shareholders' objective of maximizing the company value. The agency costs could be mitigated by, such mechanism as dividend payout, salary or 
remuneration package, regulatory mechanism, ethical and moral trainings etc. Third, Pérez, (2015) demonstrated that financial reporting depends heavily on presentation of valuable information in term of enough information quantity and quality that this will increase a firm's reputation [12]. COI between managers and owners of entities cause opportunistic behavior will end up with minimizing instead of maximizing the owners' benefits. Moral hazard would be in form of being secret actions and opportunistic behavior represented in asymmetric information. The COI eventually cause unfavorable result such as worse performance and even business failure.

\section{Information Cost}

First we show how much does producing quality information cost. Producing quality information has two components: basic cost and premium cost. Basic cost is the cost of producing quality information at basic level of reliability and quality. A reasonable cost contains fundamental part that without the information, decision cannot be made or useless at all. The cost of producing basic information supposed to be fixed cost; that is a certain amount of money to spend produce the information. However, the information to be useful for decision making, extra cost need to be spent to make the information to be at the primum level, very useful for making high quality decision(s). The premium part is a variable cost, depend on the quality level. Total actual information cost supposed to have two components of basic actual which is a fixed cost ( ) and actual premium cost which is a variable cost ( ), then:

$$
\mathrm{TIC}=\mathrm{BFC}+\mathrm{PVC}
$$

To have high quality information, entities should pay extra cost of the information contain two important characteristics: relevance and reliability. $\mathrm{C}$ defines as total cost to produce relevance and defines as total cost to produce reliable information. So, formula (1) expands to:

$$
\mathrm{TIC}=\mathrm{BFC}+\mathrm{TC}+\mathrm{TC}
$$

Each and are only variable parts. The $\square$ and are the slopes of variable cost of producing relevance and reliable information. The formula can be expanded for total cost incurred due to reliability and relevance. as:

$$
\mathrm{TIC}=\mathrm{BFC}+(\mathrm{Q} . \delta)+(\mathrm{Q} . \varphi)
$$

Formula 3 can be extending to formula (4):

$$
\mathrm{TIC}=\mathrm{BFC}+\mathrm{Q}(\delta+\varphi)
$$

Proof. When there is COI, the slop of $\delta+\varphi$ is determent of costs depend on the Q which is the quantity of the information needed to remove the COI. Companies cannot reduce basic fixed information costs but the $\mathrm{Q}(\delta+\varphi)$ would be depend on mitigating COI effects in the organizational culture. The lower the $\mathrm{Q}$, the information costs would be reduced by lower $(\delta+\varphi)$.

Transaction cost theory is relevant to our discussion and linked to information cost conception. Transaction cost theory is defined as operating costs of the economic system. By considering Arrow and Williamson discussion, information cost should be an vital part of transaction cost. In contrast to the agency theory, transaction cost theory concern about the efficiency of the corporate governance in maximizing the owners' wealth. This theory works as a mechanism to control information costs. If a company structure align with relatively efficient hierarchical shape, then the contractual relationships between the agent and principal should be at the lowest COI level. If the transactions incurred should be in ally with efficiency of governance structures, then information costs should be at the lowest level. Therefore, one effect mechanism to control information cost would be under the transaction costs 
justifications. An example of the transaction costs is the cost of designing an efficient and effective internal control systems by management in which will be controlled by the audit committee and external auditor annually.

In formula (4), if BFC is defined as the cost of designing and implementing internal control systems accompanied with supervision of the audit committee as required by SOX section 404, then $Q(\delta$ $+$

$\varphi$ ) would be the variable part. The variable part is the cost of internal and external auditor and it is variable due to the size of information which is determined by the size of the company. Normally, big firms pay higher audit fee than the small to medium-size companies. In fact, the relevance and reliability of the financial information presented by manager to the users depend on the investigation of external auditors. Thus, the formula can be extended as follows:

Where:

$$
\mathrm{TIC}=\mathrm{ICS}+\mathrm{Q}(\mathrm{IAC} .+\mathrm{EAC} .)
$$

$$
\begin{aligned}
& \text { ICS = Internal Control System at total costs } \\
& \text { IAC . = Internal auditor cost per information unit } \\
& \text { EAC . = External auditor cost per information unit } \\
& Q=\text { the size of information depends on the number of transactions }
\end{aligned}
$$

COI causes information cost to be increased as results of cost of internal and external auditors. The complexity of determining information costs amplifies when the COI integrated with the core of the corporate accounting frauds and characterized with the corporate governance issues. Corporate board of directors uses monitoring mechanism through internal and external auditors as gatekeepers. Internal auditors and audit committees are internal corporate governance gatekeepers. The external influence through two groups: external auditor (i.e., CPAs), regulatory agencies such as government (e.g., the SEC through PCAOB) and nongovernment regulators (e.g., the New York Stock Exchange).

\section{$4 \quad$ Optimal Information Quantity}

The Optimal Information Quantity (OIQ) is defined as disclosure of the optimal amount of information to be available to make effective and efficient decision(s). First, the cost of producing OIQ should be at least equal to or less than the benefit of the OIQ for every firm. Second, determining the OIQ requires a professional judgement which require to be differentiated from industry to industry, size and nature of enterprises or businesses. Therefore, for most of the firms, having an indication or measure of the optimal amount of producing information would be helpful to make reasonable decisions.

Refer to the above discussion, to compensate of the extra information costs, TIC or total actual information costs should be equal to the total benefits of producing the information. TIB is total information benefits which is either risk-free or low level risk information. In fact, similar to produce any commercial goods or services, producing information has its own cost and therefore it should have the benefit more than its cost. Therefore, TIC should be at least equal or more than TIB to be considered as cost-benefit effective action;

$$
\mathrm{TIC}=\mathrm{TIB}
$$

The TIB is defined be equal to Q. $\gamma$ in which $\gamma$ is the slope or the benefit per unit of producing the information and $\mathrm{Q}$ is the quantity of the information or OIQ.

$$
\mathrm{TIB}=\mathrm{Q} \times \gamma
$$

To make it abbreviate, we use Q. When formula (4) and (7) are expanded then we have: 


$$
\begin{aligned}
& Q . \gamma=\mathrm{BFC}+\mathrm{Q}(\delta+\varphi) \\
& \mathrm{BFC}=\mathrm{Q} \cdot \gamma+\mathrm{Q}(\delta+\varphi)
\end{aligned}
$$

To determine how much quality information to be produced that equal total cost of producing to total benefit, mangers must use the formula:

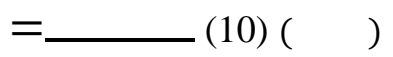

We call $-(+)=$ or contribution margin of producing useful information.

Proof. Regarding to applicability of the formula 10 and compliance risk for producing reliable financial statements for the users, is defined as the cost of design, implement and maintain a sound internal control system for a firm. Suppose the cost is $\$ 150,000$ and the cost of external audit ( ) for reducing the information risk and other non-assurance services (j) for producing more relevant information quantitatively is $\$ 100,000$ and $\$ 50,000$, respectively. for making the reliable and relevant information. Both and $\mathrm{j}$ reduce the information risk. Information risk is the risk of information contained with wrong fact in which causes making wrong decision. If the quantity number of transactions proceeded by the system was 50,000 transactions last year, then \$2 and j \$1per transaction prospectively. To find we assume a firm will be benefited of producing the optimal amount of the information of reducing the compliance risk. For example, for taxation penalization charges, if we assume the amount is, in average, $\$ 450,000$, then would be $\$ 9$ per each transaction. Putting all the information in the formula 8 , then optimal number of transactions to be produced and cost effective for the year would be 25,000 transactions per annum. At least, a firm with the above information should produce the number of transactions to reduce the risk of compliance and information.

\section{$5 \quad$ Timeliness}

Under the efficient markets theory, transparency of information to the main stakeholders at the right time is a crucial element of an effective and efficient corporate governance. Transparency of information not only about quality and quantity of the information but also revealing of the information at the right time. Quality of the information combines the relevance and reliability characteristics of the information with the quantity for supporting understandability of the information [6]. However, any day delay causes the information to become less effective and injure effectiveness of decisions of the stakeholders [5].

Real time access to the information is a crucial factor influences on the information value. This issue highlighted by section 409 of SOX ACT 2002, which issuer to disclose to the public on a rapid and current basis. Right decision(s) should always be made at the right time. It is plausible that COI cause delay in providing the information at the right time to decision maker to prevent financial reporting failure [13]. Thus, it convinces to assume a negative relationship between delay in issuing the information at the right time and information value. If the current value of quality information lessen by passing time, then the question to answer is at what rate the information quality diminished. Suppose

$$
\begin{aligned}
& \mathrm{I}=\text { Information at the right time } \\
& \mathrm{I}=\text { Information at the wrong time }
\end{aligned}
$$

The following figure shows that the value of information at the right time $\mathrm{I}=\alpha \cdot \mathrm{r}$. By assuming that information value is at the highest point of $\square$ then as delay in issuing the information occurred, the information value would be decreased and eventually to become zero at $\square$ point. 
Thus, the difference between and is called delay time and the delay rate is -t. to be more accurate, the relationship assume to be non-linear. To measure how long will it take that the value of information, we developed the model. If

$=$ information value at the right time

$=$ information value at the wrong time

$=$ rate of negative return per day at the right time

= delay time to make the information value at the right to zero

$$
\text { ( ) }()=
$$

$$
\text { ( ) }
$$

If $\lim \quad=0$ where $t$ is the day when the information value would be zero, then the formula change to: $\rightarrow()$

$$
=(12)(\quad)
$$

Figure 1 presumes, based on the paper, the negative effects of COI and information quality by looking at the three important characters: optimal quantity, time and cost.

Figure 1. Theoretical Framework of COI Effects on Information Quality

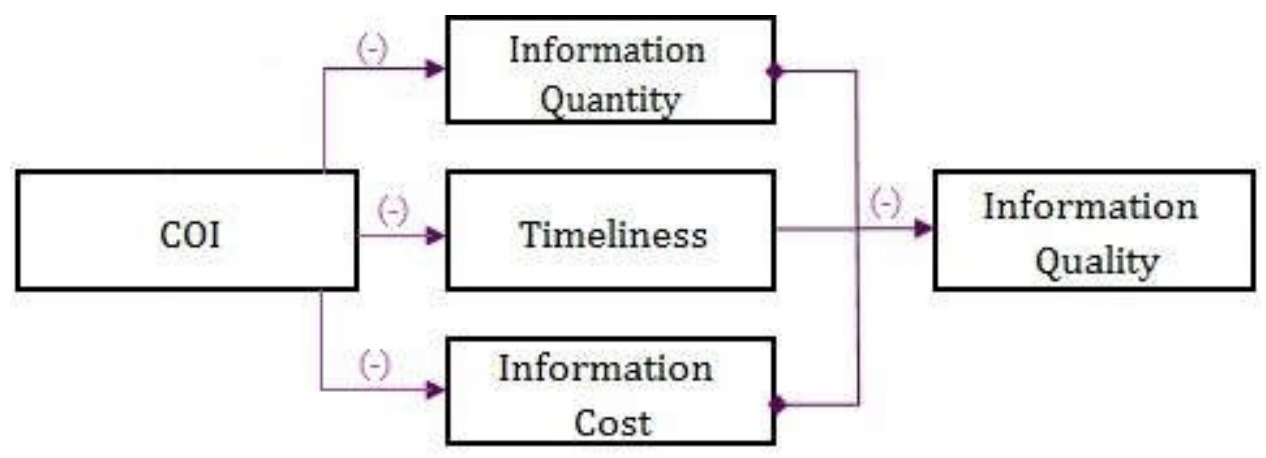

\section{COI Solutions}

This section provides solutions to COI problem and answer the question of how to minimize the COI effect(s) on timeliness, cost and optimal quantity of information by refer to the equations developed in this study. Refer to formula 4, if Q considers to be constant, the information costs would be reduced by lower $(\delta+\varphi)$. Indeed, if $(\delta+\varphi)$ suppose to be constant, then Q should be lower to reduce COI. Regarding optimal quantity of information, if should be more than $(+)$. By refer to equation 10, the bigger

, then would be lower, therefore, this would be more economical for entities. By refer to equation 12, companies should elevate $(1+)$, in which precisely this means that $r$ should be higher.

\section{Conclusion}

This research mathematically showed how to measure COI and how it negatively impacts on management decision making by decreasing optimal information quantity, increasing information costs and make a longer period to produce quality information. While the interior effect of COI on management decision 
and entities performance has been examined extensively in management and other disciplines' literature, little is known about how to measure the harmful effect of COI on information quality. This study has provided evidence which suggest the ways of decreasing the negative effects of COI on information quality. The results therefore largely support many other empirical studies of the effect of COI on management decision in form of lowering information quality.

\section{References}

1. Akerlof, George A. (1970). "The Market for 'Lemons': Quality Uncertainty and the Market Mechanism". Quarterly Journal of Economics. The MIT Press. 84 (3): 488-500.

2. Boltona, P., Freixasb, X., \& Shapiro, J. (2007). Conflicts of interest, information provision, and competition in the financial services industry. Journal of Financial Economics(85), 297-330.

3. da Cunha, P. R., \& Piccoli, M. R. (2017). Influence of board interlocking on earnings management *. Revista Contabilidade \& Finanças, 28(74), 179-196.

4. ECI (2016). Conflicts of Interest Ethics and Compliance Initiative. USA: Ethics Research Center (ERC).

5. Ezat, A., \& El-Masry, A. (2008). The impact of corporate governance on the timeliness of corporate internet reporting by Egyptian listed companies. Managerial Finance, 34(12), 848-867.

6. Gullberg, C. (2016). What makes accounting information timely? Qualitative Research in Accounting and Management, 13(2), 189-215.

7. Lim, Y., \& Jung, K. (2012). Conflict of Interest or Information Sharing? Evidence from Affiliated Analyst Performance in Korea. Contemporary Accounting Research, 29(2), 505-537.

8. Makni, I., Kolsi, M. C., \& Affes, H. (2012). The impact of corporate governance mechanisms on audit quality: Evidence from Tunisia. IUP Journal of Corporate Governance, 11(3), 48-70

9. Mehrana, H., \& Stulz, R. M. (2007). The economics of conflicts of interest in financial institutions. Journal of Financial Economics(58), 267-296.

10. Mohd-sulaiman, A. (2013). Financial reporting failures, board's competency and effectiveness. International Journal of Disclosure and Governance, 10(2), 155-174.

11. Nelson, W. A., William B, Justin M., MacLeod, L.,(2008) The Organizational Costs of Ethical Conflicts. Journal of Healthcare Management; pp.41-53.

12. Pérez, A. (2015). Corporate reputation and CSR reporting to stakeholders. Corporate Communications, 20(1), 11-29.

13. Pizzo, M. (2013). Related party transactions under a contingency perspective. Journal of Management \& Governance, 17(2), 309-330.

14. Xie, L. (2007). Universal banking, conflicts of interest and firm growth. Journal of Financial Services Research, 32(3), 177-202. 